\title{
Understanding Collective Action through Relationships: A Study on the Turkish 2013 Uprising (occupy Gezi)
}

${ }^{1}$ Middle East Technical University, ${ }^{2}$ Tilburg University, ${ }^{3}$ University of Oslo/Harvard University

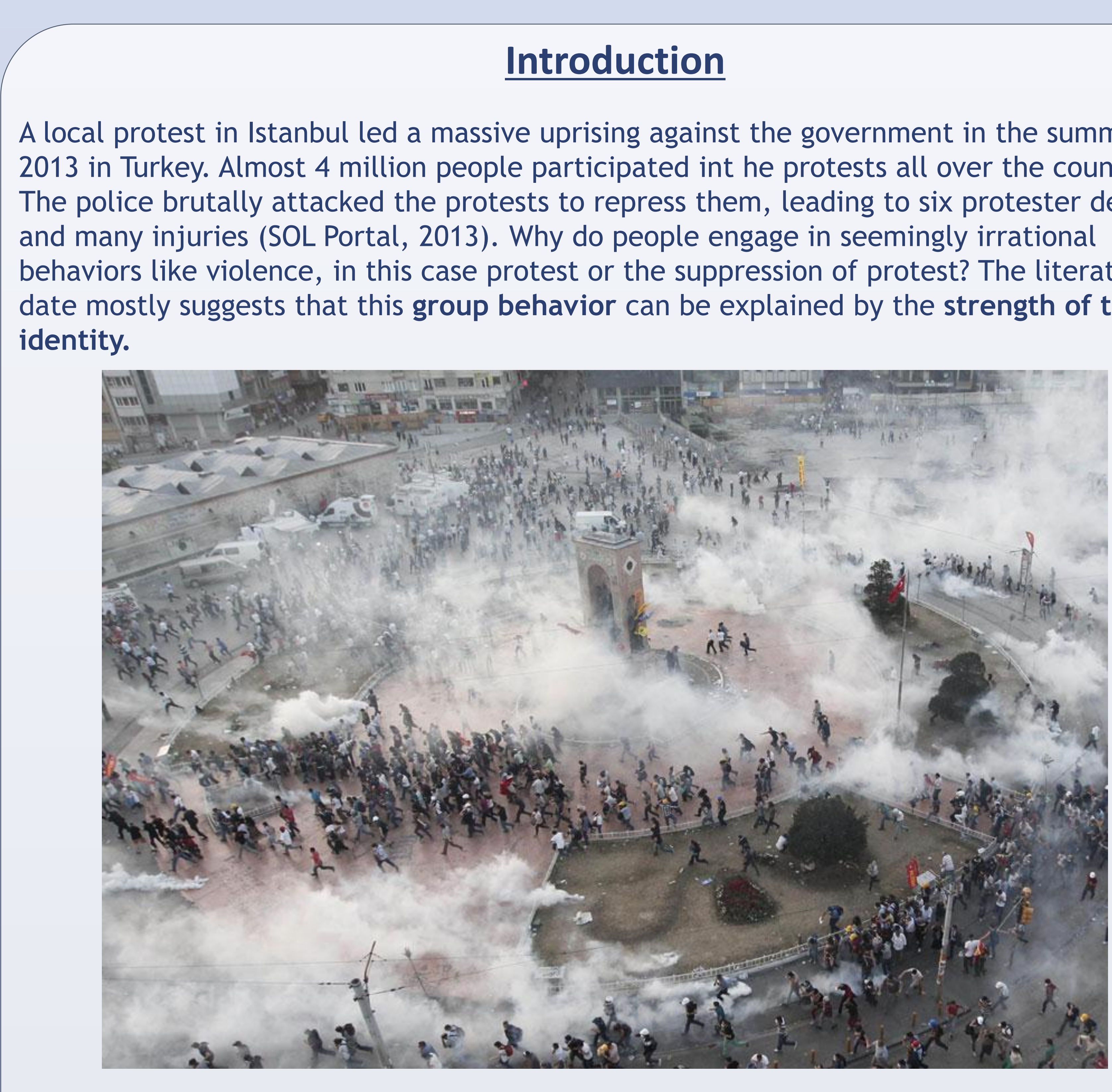
However, the strength of people's identities does not explain when identity strength is a
sufficient motive to engage in such protests, and it also does not predict which side of a

In this research, we investigated people's motives to explain why they support either side in the Turkish Uprising. Specifically, we depart from a framework that suggests that people's moral motivations to engage in violence are relationally motivated. The
we analyze here are unity and hierarchy (Fiske, 2004; Rai \& Fiske, 2011).

Unity is the moral motive that directs people to care and protect their group members, without need for reciproctiy. Acting for group integrity and sacrifice for the group is t for Communal

Hierarchy organizes relationships around a linear hierarchy, expecting and showing and guidance). This moral motive is specifically relevant for Authority Ranking (AR) Relationships.

Supporting the uprising against Turkish government or opposing the protests can be relationships with different social groups (protesting groups vs. government supporters).

In this study we would like to find out answers the following questions: 1.Do general preferences for CS and AR relationships predict support for and engagement in the protests? (RM Preference)

2.Does the implementation of CS and AR towards specific groups (i.e., protestors, gover 3.Does group identification mediate the association between relational model preferences 4.Does group identification mediate the association between CS implent
for and engagement in the protests? (RM Implementation Mediation)

\section{Method}

Participants: 641 (62.4\% women)

Online Survey Package:

Circles in Relational Configuration Arrays (CIRCA; Thomsen, 2010; RM Preferences)

(2)

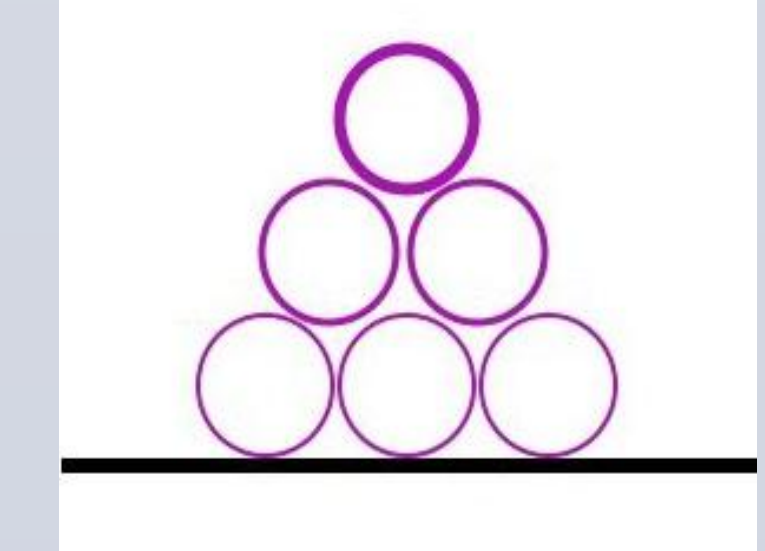

-Modes of Relationships Questionnaire (MORQ; Haslam \& Fiske, 1999; RM Implementations) -Collective Identity (e.g., I feel commitment to protesters and people that attend in demonstrations"; rated on a 6-point scale from 1 "not at all" to 6 "too much"; questions

-Attitudes towards Turkish Uprising (Six items, e.g., "I support protests and

-Did you participate in the protests in some way? (“Yes/ No"; engagement)

\section{Results}

Support for the protests - Table 1 depicts:

CS preferences positively predicted supporting the protests

AR preferences negatively predicted supporting the protests.

entation towards family relations negatively predicted support for

CS implementation towards protesting groups was positively related to

support for the protests, but CS with supporters of government was negatively

related to support for the protests.

\begin{tabular}{|c|c|c|c|}
\hline \multirow{3}{*}{$\begin{array}{l}\text { Table 3. R } \\
\text { Model } 1\end{array}$} & & & \\
\hline & Variables & $B(S E)$ & $95 \% \mathrm{Cl}$ \\
\hline & $\begin{array}{l}\text { CS Preference } \\
\text { AR Preference }\end{array}$ & $\begin{array}{l}.07(.02) \\
. .2(1.03)\end{array}$ & . \\
\hline Model 2 & $\begin{array}{l}\text { Adj. R2 } \\
\text { CS implementatation fintily }\end{array}$ & $\begin{array}{l}.04 * \\
.05(.03)\end{array}$ & $-.02-.11$ \\
\hline & Adj. R2 & $.02 *$ & \\
\hline & $\begin{array}{l}\text { CS with protestiting groups } \\
\text { AR with protesting groups }\end{array}$ & $\begin{array}{l}.38(.03) \\
-.04(.03) \\
\text { (a) }\end{array}$ & $\begin{array}{l}-33-43 \\
-.09-01\end{array}$ \\
\hline Model 4 & $\begin{array}{l}\text { Adj. R2 } \\
\text { met sup. }\end{array}$ & & \\
\hline & & .03 & $-01-.08$ \\
\hline
\end{tabular}

2. Engagement in the protests - Table 2 depicts active engagement:

Higher CS preferences was related to increased probability of engagement in the protests.

the protests.

was related to increased probabiliity of

engagement in the protests.

Greater CS implementation with protesting groups was related to increased

probablity of engagent in the protests.

orters was related to

decreased probability of engangement in the protests.

\begin{tabular}{|c|c|c|c|c|c|}
\hline & $X^{2}(N=641)$ & $B(S E)$ & $p$ & $\operatorname{Exp}(B)$ & $95 \% \mathrm{Cl}$ \\
\hline $\begin{array}{l}\text { Step } 1 . \\
\text { CS Preference }\end{array}$ & & . $18(.09)$ & .04 & 1.20 & $1.01-1.43$ \\
\hline $\begin{array}{l}\text { AR Preference } \\
\text { Sten? }\end{array}$ & & -266..11) & & .77 & $.61-.96$ \\
\hline $\begin{array}{l}\text { Step 2.2. } \\
\text { Collective Identity with protesters }\end{array}$ & 92.85 & $89(.10)$ & .00 & 2.44 & $1.99-2.99$ \\
\hline & 21.04 & & & & \\
\hline $\begin{array}{l}\text { CS with Family } \\
\text { AR with Family }\end{array}$ & & 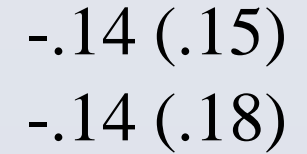 & .42 & .86 & 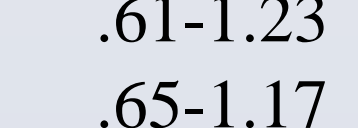 \\
\hline CS with Protesters & & $.57(.18)$ & . 001 & 1.76 & 1.25-2.49 \\
\hline AR with Protesters & & -26(.19) & .16 & .77 & .53-1.11 \\
\hline $\begin{array}{l}\text { CS with Gov. Supp. } \\
A R \text { with Gov Sunp }\end{array}$ & & 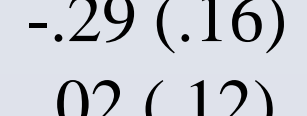 & ol & in & $\begin{array}{c}55-1.03 \\
80-13\end{array}$ \\
\hline
\end{tabular}

Mediation analyses

Collective identity with protesters mediated the relationship between CS preferences Cor preferences with support for the protests (Figure 1).

Higher CS preference was related to greater identification with protesters which is tum was related to higher support for the protests. Higher AR preference was related to lesser identification with protestors,

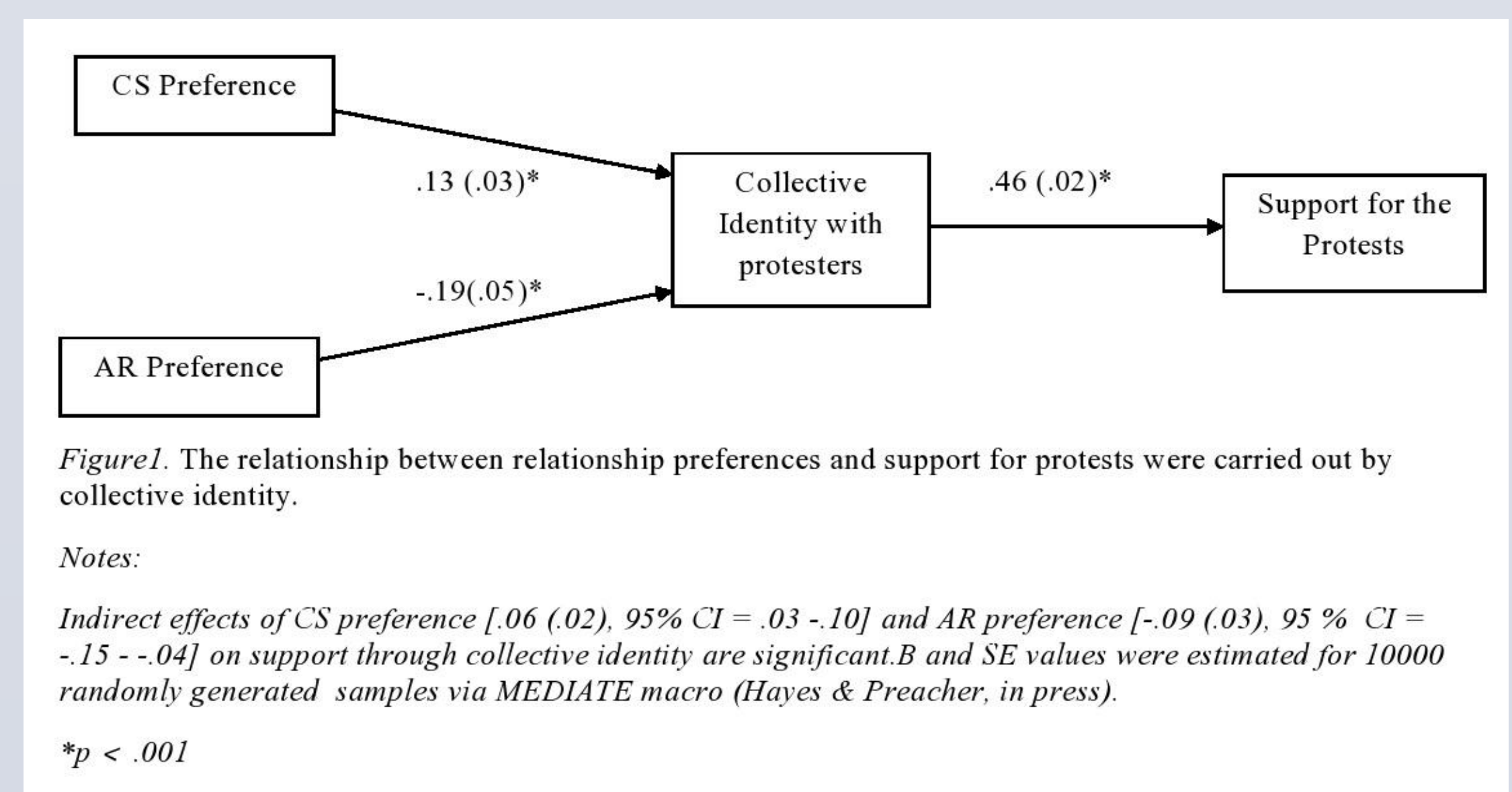

Collective identity mediated the relationship between CS implementations and support for the protests (Figure 2)

CS implementations with protesting groups was related to greater the

CS implementations with government supporters was negatively related to protests.

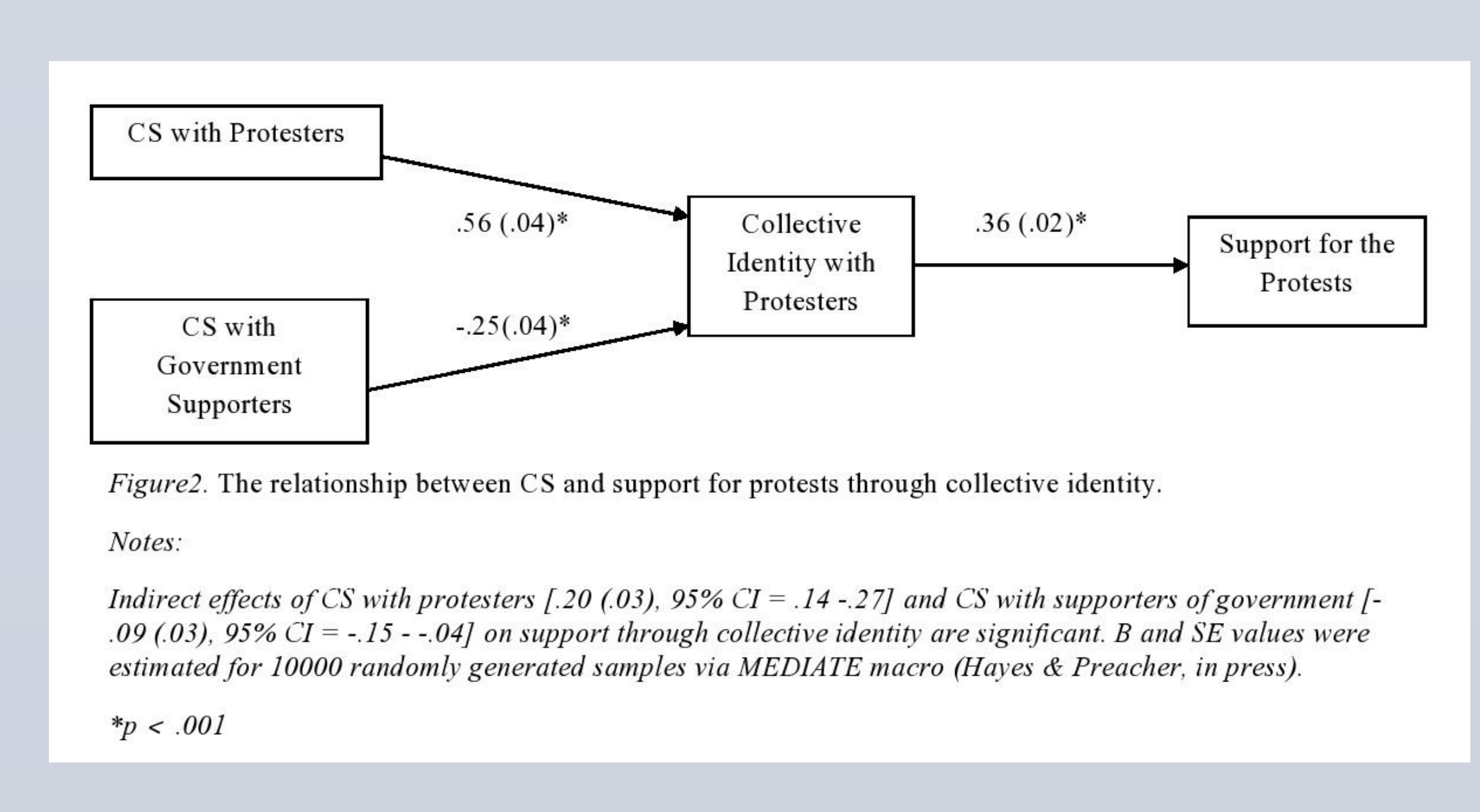

Conclusion

The results answered the question whether general preferred relational motives is related

Most notably, CS Preferences was related to greater support for the protests and to greater engagement in the protests, whereas AR preferences was related to lesser support for the protests and lesser engagement in the protests.

Less suprising was the split for CS, as greater CS with government supporters was related to lesser support for the protests (also less propensity to engage), but greater CS with

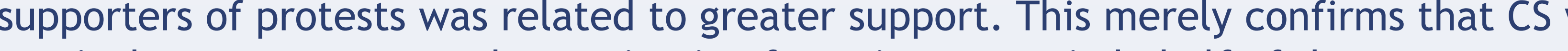
particular group prompts the motivation for unity, to act in behalf of the group.

Interestingly enough, the preference for AR revealed a consistent root, as greater AR support for the protests. The negative effect of AR relationships might reflst the morat fear of losing social order and status quo. Further, prefering AR in groups and using hierarchical motives in familial relations could be related to effects of ideological orientations as described in social dominance and right-wing authoritarianism (Thomsen, 2010

The results revealed that communal sharing preference had an indirect effect on supporing collective action through collective identity. This result provided further support communal sharing in their relationships (Rai \& Fiske, 2011). If people use communal sharing motives to relate others they are more likely to take part in collective action when their groups had.

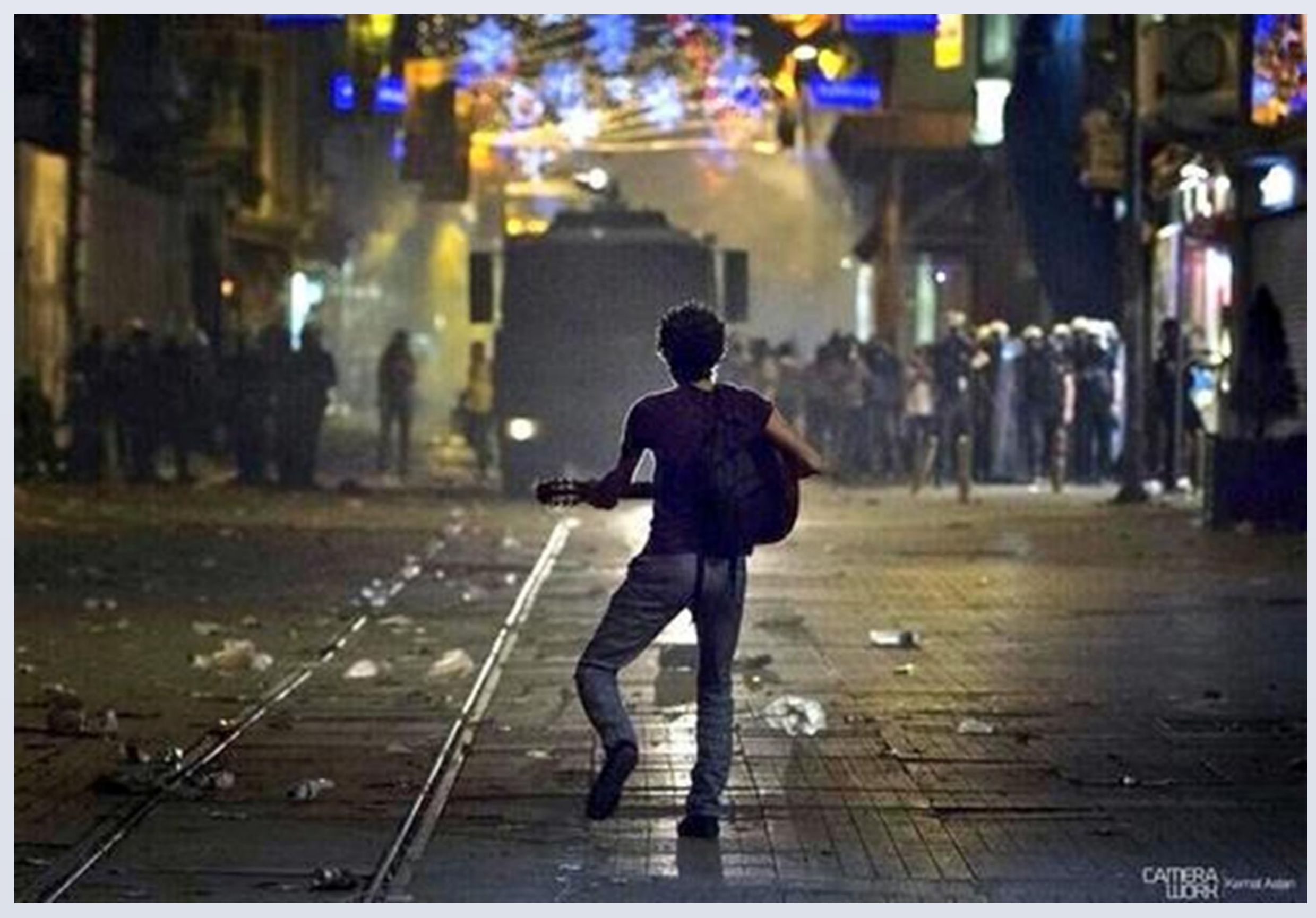

References



